Document downloaded from:

http://hdl.handle.net/10251/78886

This paper must be cited as:

Cano Embuena, Al.; Cháfer Nácher, MT.; Chiralt Boix, MA.; González Martínez, MC. (2016). Biodegradation behavior of starch-PVA films as affected by the incorporation of different antimicrobials. Polymer Degradation and Stability. 132:1-10. doi:10.1016/j.polymdegradstab.2016.04.014.

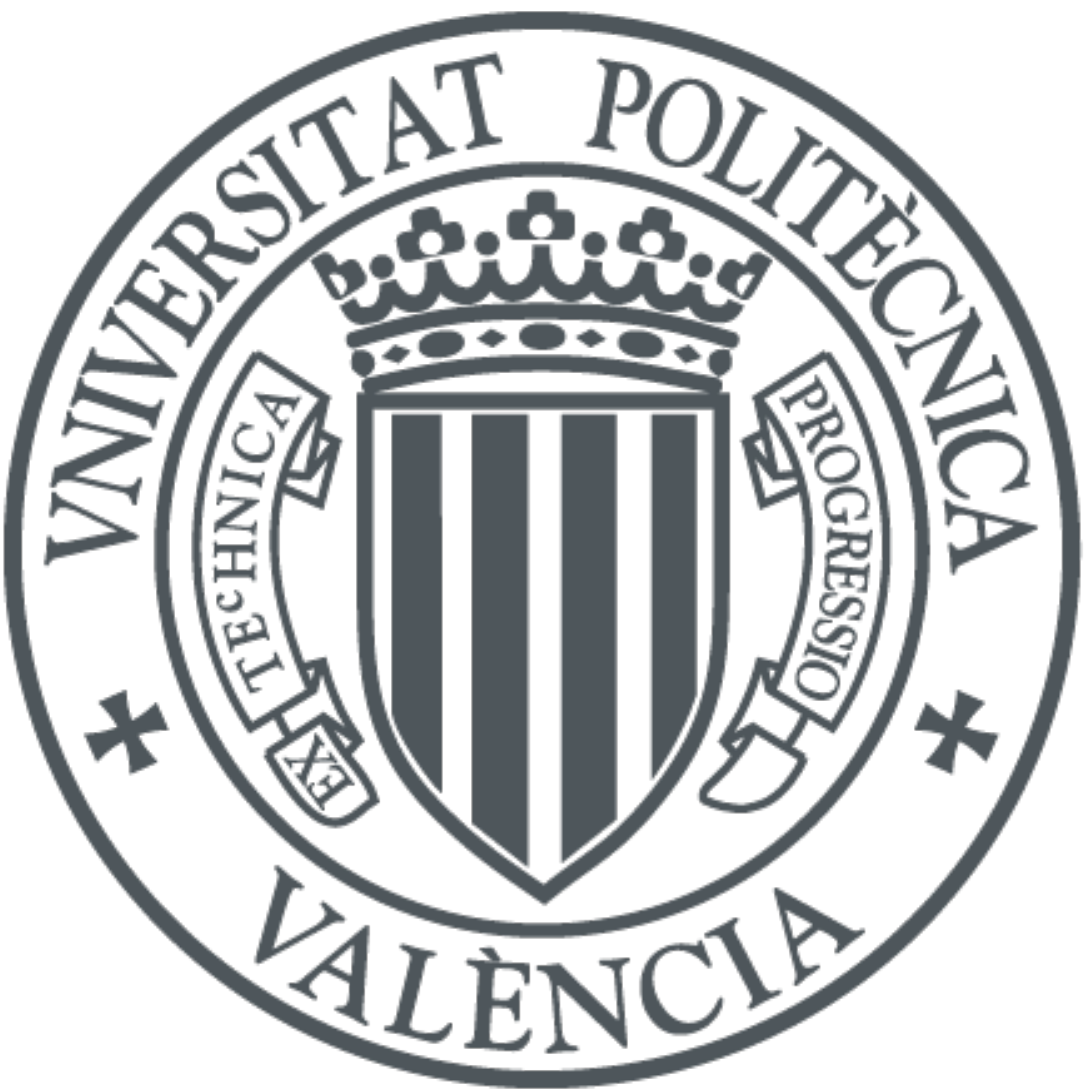

The final publication is available at

http://dx.doi.org/10.1016/j.polymdegradstab.2016.04.014

Copyright Elsevier

Additional Information 


\title{
BIODEGRADATION BEHAVIOR OF STARCH-PVA FILMS AS AFFECTED BY THE INCORPORATION OF DIFFERENT ANTIMICROBIALS.
}

\author{
Amalia I. Cano, ${ }^{(1)}$, Maite Cháfer ${ }^{(1)}$, Amparo Chiralt ${ }^{(1)}$, Chelo González-Martinez ${ }^{(1)}$ \\ ${ }^{(1)}$ Instituto de Ingeniería de Alimentos para el Desarrollo, Universitat Politècnica de \\ València. Camino de Vera s/n 48022 Valencia, Spain.
}

\section{Abstract}

The effect that the incorporation of different antimicrobial substances into S-PVA films had on their disintegration and biodegradation process was analyzed. To this end, starch, PVA and S-PVA films containing different concentrations of neem oil, oregano essential oil and silver nanoparticles were submitted to composting conditions in order to determine the disintegration and biodegradability percentages for 73 and 45 days, respectively. Additionally, thermogravimetric and structural analyses were also carried out throughout the composting period. The biodegradation and disintegration behavior of S-PVA films was intermediate between S and PVA films. The addition of neem and oregano essential oils slightly affected the biodegradation and disintegration profile of starch-PVA films, enhancing both disintegration and biodegradation levels. So, the presence of these antimicrobials did not compromise the compostable and biodegradable character of the starch-PVA blend films. Nevertheless, the biodegradation capacity of films containing $9.8 \%$ silver species was seriously affected, reaching values of only $58 \%$ after 45 days of composting, despite their high disintegration capacity. Thus, lower silver concentrations are recommended in order to avoid possible alterations in compost microbial activity.

Key words: Neem oil; oregano essential oil; silver nanoparticles; composting process; disintegration.

\section{Introduction}


Most of the conventional plastics are non-biodegradable and remain for 100-450 years in the environment [1]. Currently, the methods employed to handle the plastic wastes include incineration and recycling, but they are insufficient for the purposes of solving the environmental problems. As an alternative, biodegradable plastics have attracted growing attention because of their potential use in the replacement of traditional non-degradable plastic items deriving from fossil fuel feed stocks so as to ensure a significant contribution to sustainable development in view of the wider range of disposal options causing a lower environmental impact [2].

Composting is an aerobic process designed to produce stabilized organic residues from the biodegradable parts of packaging waste under controlled conditions and using microorganisms [3]. Nowadays, in the area of food packaging, studies focus on the disintegration, biodegradability and ecotoxicity properties of films under compostable, controlled conditions in order to evaluate their behavior. In this sense, new ISO standards establish methodologies, where specific disposal pathways, specific time frames and passing criteria are indicated in order to unify a proper composting analysis of plastics.

On the other hand, considerable pressure has been placed on the need to pay attention to current consumer eating habits; food which is healthier, free of synthetic chemical substances and sustainably manufactured has boosted research into the development of new food packaging which should provide protection against chemical, physical and biological agents [4]. The incorporation of natural active substances into biodegradable film matrices is currently an alternative means of preventing food spoilage [5] for the retardation of deterioration, the extension of shelf-life, and the maintenance of the quality of foodstuffs. In this sense, essential oils, their pure compounds, clays, peptides, proteins and substances from mineral source such as silver, gold, zinc, etc. have been widely used as antimicrobial substances into film matrices due to their strong activity against both bacteria and fungi [4]. Their antimicrobial activity cannot be explained by a single specific mechanism for some substances, and in other cases it is still not known, although in the most of them the 
mechanism of action is normally related with the interactions between active substances and cellular membrane leading to changes on its permeability and the subsequent inhibition or reduction of microorganisms.

It is well known that some biopolymers, such as starch and PVA, are suitable biodegradable materials which are able to form blend films with proper physical properties [6]. In addition, their blends form interpenetrated polymer networks with beneficial effects on the film properties, mainly enhancing the water vapour barrier and mechanical properties, the films becoming much more stretchable and stable during storage [6]. Both pure and blend films could act as carriers of bioactive substances, such as antimicrobials. These films could help to decrease food spoilage while extending its shelf life. Of the natural antimicrobial substances, essential oils and silver nanoparticles have proven to exhibit an interesting activity against a wide variety of microorganisms $[7,8,9]$.

However, the incorporation of films containing active substances into the compost could affect the biodegradation behaviour. There have been few studies into the degradation processes of films containing antimicrobial substances $[10,11]$. It is likely that the different additives incorporated into the film will affect the degradation processes because of their antimicrobial activity could disturb inoculum of the compost or/and introduce a tortuous path leading to a slower diffusion of enzymes [10]. In addition, although the biodegradation of both polymers has been reported by different authors $[12,13,14]$ and for S-PVA blend films $[15,16,17]$, scarce information has been found.

The aim of the present study was to analyse the effect of incorporating antimicrobial substances into S-PVA blend films on their disintegration and biodegradation under controlled composting processes. Thermogravimetrical, structural and visual analyses were also analysed throughout the composting period.

\section{Materials and Methods}




\subsection{Materials}

Pea starch (S) (amylose:amylopectin ratio 1:3.0 [16]) was supplied by Roquette Laisa España S.A. (Benifaió, Valencia, Spain), poly(vinyl alcohol) (PVA) ( $M_{w}: 89,000-98,000$, degree of hydrolysis $>99 \%$, and viscosity at $4 \% \mathrm{H}_{2} \mathrm{O}, 20{ }^{\circ} \mathrm{C}$ is $11.6-15.4 \mathrm{cP}$ ) was purchased from Sigma Aldrich Química S.L. (Madrid, Spain) and glycerol and phosphorus pentoxide $\left(\mathrm{P}_{2} \mathrm{O}_{5}\right)$ were provided by Panreac Química S.A. (Castellar de Vallès, Barcelona, Spain).

Different bioactive substances used for the study were: neem oil (NO) purchased from Magnolia Holland Ibérica S.A. (Vilassar de Mar, Barcelona, Spain), oregano essential oil (OEO) from Herbes del Molí (Benimarfull, Alicante, Spain) and silver nitrate $\left(\mathrm{AgNO}_{3}\right)$ from Sigma Aldrich Química S.L. (Madrid, Spain) to obtain the silver nanoparticles (AgNPs).

\subsection{Preparation of film forming dispersions and films}

Films were obtained by means of the solvent casting procedure after the preparation of film forming dispersions (FFDs). Starch $(2 \% \mathrm{w} / \mathrm{w})$ was dispersed in an aqueous solution at 95 ${ }^{\circ} \mathrm{C}$ for $30 \mathrm{~min}$ to induce starch gelatinization. Thereafter, the dispersion was homogenized using a rotor-stator homogenizer (Ultraturrax D125, Janke and Kunkel, Germany) at 13,500 rpm for $1 \mathrm{~min}$ and 20,500 rpm for $3 \mathrm{~min}$. Afterwards, PVA was incorporated into the starch dispersion in a S:PVA ratio of $2: 1$ and the dispersion was maintained at $90{ }^{\circ} \mathrm{C}$ for $30 \mathrm{~min}$ under stirring until complete dissolution. Finally, glycerol was added in a starch:glycerol ratio of $1: 0.25$, on the basis of previous studies [18]. This FFD is used to obtain the control films (S-PVA) and to incorporate the antimicrobial substances. Moreover, starch-glycerol and PVA FFDs were also obtained by the same procedure in order to obtain pure films for comparative analyses.

S-PVA film forming dispersions containing AgNPs were obtained by a green synthesis method. The reduction of $\mathrm{AgNO}_{3}$ was induced by means of using UV light as reducing agent [19] and the starch and PVA present in the FFD acted as polymeric stabilizers [20]. $\mathrm{AgNO}_{3}$ was added to the S-PVA FFD at different weight ratios with respect to starch 1 : 0.006 , 
1:0.06, 1:0.16 and 1:0.32) and the mixtures were maintained at $90{ }^{\circ} \mathrm{C}$ for 30 min under stirring and UV radiation till the dispersion turned brown due to the formation of AgNPs. The reduction of silver ions with the formation of AgNPs was monitored by using a DU 730 spectrophotometer (Thermo scientific, Helios UV-VIS, England).

In the case of neem oil and oregano essential oil, two S:oil ratios were considered (1:0.5 and 1:0.125). After oil was added to the FFD, homogenization was carried out at 12,500 rpm for $4 \mathrm{~min}$ in order to emulsify the lipid. FFDs, containing or not antimicrobials, were poured into Teflon casting plates $(15 \mathrm{~cm}$ diameter) in the right amount to provide a surface solid density of 84.8 g.m ${ }^{-2}$. The films were dried at $25^{\circ} \mathrm{C}$ and $45 \% \mathrm{HR}$ for $48 \mathrm{~h}$ and afterwards, peeled off the casting surface. Afterwards, the film thickness was measured at six random positions with a Palmer digital micrometer to the nearest $0.0025 \mathrm{~mm}$. Table 1 shows the different formulations of active films and their sample codes.

\subsection{Compost conditioning and characterization}

For both tests, that of disintegration and the biodegradation test, the ripe compost was supplied by a plant composting the organic fraction of solid municipal waste in order to ensure sufficient diversity of microorganisms.

For the disintegration test, a solid synthetic waste was formulated on the basis of the ISO 20200 International Standard [21].

For the biodegradation test, ripe compost was mixed with vermiculite to prevent the compost compaction, thus ensuring a good oxygen access. Afterwards, the water content was adjusted to 50 - $55 \%$ in total, for both test /media. Aerobic conditions were guaranteed in the medium by mixing gently. The compost was sticky and without free water. These conditions were maintained throughout the assay by adding de-ionized water to ensure a proper composting process.

The dry mass (DM) and the burned-out solid (BS) content of the control sample's synthetic waste before and after the composting process were determined in triplicate according to ISO 20200:2004. The DM was obtained by drying the sample in a convection oven at 105 
ㅇ C until constant weight (Eq. (1)) whilst the BS was evaluated by treating the dried samples in a muffle to obtain ash (Selecta, Barcelona, Spain) at $550 \stackrel{\circ}{\mathrm{C}}$ until constant weight (Eq. (2)). The $\mathrm{C} / \mathrm{N}$ ratio was also determined according to the standard ISO.

$\operatorname{DM}(\%)=\frac{\mathrm{W}_{\mathrm{d}}^{105}}{\mathrm{~W}_{\mathrm{w}}^{\mathrm{i}}} x 100$

$\operatorname{BS}(\%)=\frac{\mathrm{W}_{\mathrm{d}}^{105}-\mathrm{W}_{\mathrm{d}}^{550}}{\mathrm{~W}_{\mathrm{d}}^{105}} \times 100$

where $W_{W}^{i}$ is the initial weight of the sample, $W_{d}^{105}$ is its weight after drying at $105^{\circ} \mathrm{C}$ and $\mathrm{W}_{\mathrm{d}}^{550}$ is the weight of the ashes after the treatment at $550^{\circ} \mathrm{C}$.

\subsection{Disintegration test}

Laboratory-scale disintegration tests were carried out on S, PVA, S-PVA and composite films during the thermophilic incubation period under composting conditions following an adapted method based on the current ISO 20200: 2004 International Standard. Approximately $5 \mathrm{~g}$ of film samples $(25 \times 25 \mathrm{~mm})$ were weighed using an analytical balance $( \pm 0.00001 \mathrm{~g})$ and then placed in the reactors containing $1 \mathrm{~kg}$ of the produced synthetic waste. Reactors were also weighed (Sartorius, Goettingen, Germany) and placed into an oven (Selecta, J.P. Selecta S.A., Barcelona, Spain) at $58 \pm 2 \stackrel{\circ}{\mathrm{C}}$ for 73 days. Throughout the test, the reactors were also weighed and, if needed, the initial mass was restored totally or partially by adding de-ionized water. For each sample, 4 reactors were tested: 3 for the calculation of the percentage of disintegration (D, Eq. (3)) after the composting period, and 1 for the monitoring of the studied films during the process by thermogravimetric, structural and appearance analyses ( $\mathrm{t}=0$ and 73 days).

$D(\%)=\frac{m_{i}-m_{r}}{m_{i}} \times 100$

where $m_{i}$ is the initial dry mass of the samples and $m_{r}$ is the dry mass of the residual tested material.

\subsection{Film characterization techniques}




\subsubsection{Moisture content}

Moisture content (MC) was evaluated by film drying following the method described by Cano et al. [6]. Firstly, samples were dried in a vacuum oven at $60{ }^{\circ} \mathrm{C}$ for $24 \mathrm{~h}$. Later on, the predried samples were transferred to desiccators containing $\mathrm{P}_{2} \mathrm{O}_{5}$ until reaching a constant weight. Five replicates per film formulation were analysed before the composting process.

\subsubsection{Structure and visual appearance}

The microstructural analysis of the films was carried out by using optical microscopy (Leica, model DM LM, Química y Medio Ambiente S.L., Spain). To this end, films were dried in a vacuum oven at $60{ }^{\circ} \mathrm{C}$ for 1 week, before the observations. Two replicates per formulation/time were observed at a magnification of $63 \mathrm{X}$ at time 0 and after 73 days of the composting period. Microscopy images were captured and digitised by a video module Leica ICC A (Integrated Camera Compound-Analogue) using the Leica IM50 v. 1.2 software.

In order to analyse the changes in the film's appearance and surface area, photographs of film samples were taken by using a digital camera (Stylus XZ-2, Olympus, Indonesia) and image analyses were performed by using the Photoshop CS4 (Adobe Systems Software Ireland) to determine the total area reduction of the films during composting.

\subsubsection{Thermogravimetric analysis (TGA)}

A thermogravimetric analyzer (Mettler Toledo, Switzerland) was used to obtain the thermal weight loss (TG) curve, and its derivative (DTG), of the samples. To this end, approximately $10 \mathrm{~g}$ of sample were poured into an alumina crucible and heated from $25{ }^{\circ} \mathrm{C}$ to $600{ }^{\circ} \mathrm{C}$ at 10 ${ }^{\circ} \mathrm{C} / \mathrm{min}$, using nitrogen flow. The onset, peak and end temperatures $\left(T_{0}, T_{p}\right.$ and $T_{e}$, respectively) were obtained for each degradation step in the films. These temperatures were obtained from the TG curves (weight loss vs temperature) by using a specific software. The program calculates the extrapolated onset temperature that denotes the temperature 
at which the weight loss starts. The peak temperature (maximum degradation rate) is obtained from the inflection point of the curve TG curve and the end temperature, the point at which the weight loss is finished.

Prior to the analyses, the samples were dried in a convention oven at $60{ }^{\circ} \mathrm{C}$ for one week and then were transferred to a desiccator with $\mathrm{P}_{2} \mathrm{O}_{5}$ until constant weight was reached to ensure complete drying. The measurements were taken in duplicate for each film, before and after 73 days of the composting process.

\subsection{Biodegradation test}

The ultimate aerobic biodegradation level of films was tested under controlled composting conditions following the method adapted from the EN ISO 14855-1: 2012 European Standard [22]. The test is based on the measurement of the $\mathrm{CO}_{2}$ generated in the process, which is considered proportional to the percentage of biodegradation.

Prior to the test, the $\mathrm{C}, \mathrm{N}$ and $\mathrm{H}$ content of the different samples was determined by elemental analysis (Elemtan, microanalyzer, Eager 200, Micro TruSpec de LECO instrumentos S.L., Madrid, Spain) in duplicate.

For the biodegradation test, the bioreactor consisted of a hermetic 2 litre glass jar, containing two $60 \mathrm{~mL}$ polypropylene flasks. One of them contained $3 \mathrm{~g}$ of dry compost mixed with $50 \mathrm{mg}$ of equivalent carbon ground dry samples and $1 \mathrm{~g}$ of vermiculite. The other flask contained de-ionized water in order to ensure $100 \% \mathrm{RH}$. The bioreactors were closed and incubated at $58 \pm 2{ }^{\circ} \mathrm{C}$ for 45 days. The S, PVA, S-PVA and composite films with the highest concentrations of each antimicrobial compound (S-PVA-O2, S-PVA-N2 and S-PVA-Ag4) were tested. The blank samples contained only compost, and CMC (cellulose microcrystalline from Sigma Aldrich Química S.L., Madrid, Spain) mixed with compost as a reference sample was also analysed. All samples were measured in triplicate. 
The change in the gas composition inside each bioreactor was monitored during the biodegradation process by means of an $\mathrm{O}_{2}$ and $\mathrm{CO}_{2}$ gas analyser (Dansensor, Checkmate 9900, Spain).

The theoretical amount of $\mathrm{CO}_{2}$ (Eq. 5) corresponding to the total sample degradation and the percentage of biodegradation (Eq. 6) was calculated following Balaguer et al. [10] assuming that for a degraded sample, all the carbon was converted into $\mathrm{CO}_{2}$.

$C O_{2}^{T h}=W S x \operatorname{Cs} x \frac{M W c o_{2}}{M W c}$

$B(\%)=\frac{\sum C O_{2 s}-\sum C O_{2 B}}{C O_{2}^{T h}} \times 100$

where $W s$ is the dry weight of the samples, $C s$ is the proportion of organic carbon in the dry samples and, $\mathrm{MWCO}_{2}$ and $\mathrm{MWc}$ are the molecular weights of carbon dioxide and carbon, respectively. $\sum \mathrm{CO}_{2 \mathrm{~S}}$ and $\sum \mathrm{CO}_{2 B}$ are the accumulative amounts of $\mathrm{CO}_{2}$ produced in the sample and blank bioreactor, respectively.

The Hills equation (Eq. 7) was used to fit kinetics of sample biodegradation:

$\% B=\% \operatorname{Bmax} x \frac{t^{n}}{k^{n}+t^{n}}$

where $=\% B \max$ is the percentage of biodegradation at infinite time, $\mathrm{t}$ is the time, $\mathrm{k}$ is the time at which $50 \%$ of the maximum biodegradation occurred $(0.5 \% \operatorname{Bmax})$ and $n$ is the curve radius of the sigmoid function.

\subsection{Statistical analysis}

Statgraphics Centurion XV.I (Manugistics Corp., Rockville, MD) was used in order to carry out the statistical analysis of results through analysis of variance (ANOVA). To differentiate samples, Fisher's least significant difference (LSD) was used at the $95 \%$ confidence level.

\section{Results and discussion}

3.1. Compost properties 
The dry matter (DM), burned-out solids (BS), as a measurement of the organic matter content, and the $\mathrm{N} / \mathrm{C}$ ratio of the synthetic compost used were $143 \pm 6,96 \pm 2$ and $48 \pm 2$, respectively before the film composing process and $93 \pm 5,88 \pm 3$ and $42 \pm 2$, respectively, at the end of process. The three parameters significantly decreased $(p<0.05)$ after 73 days of the composting period, due to the aerobic activity of the microorganisms involved in the fermentation at $58{ }^{\circ} \mathrm{C}$. The fermentation also provoked some colour changes in the compost, which turned darker, coinciding with that observed by other authors [23].

\subsection{Moisture content and thickness of films}

The moisture content $(\mathrm{MC})$ of pure starch and PVA films was $4.6 \%$ and $6.85 \%$, respectively. The MC values for blend S-PVA films, both with and without antimicrobials, ranging between $4.6-6.4 \%$, are shown in Table 1 . In general, MC values were not significantly affected by the incorporation of the different antimicrobial agents. Likewise, blend film thickness values ranged between 58-74 $\mu \mathrm{m}$ (Table 1) and for neat polymer matrices, these were between $60-80 \mu \mathrm{m}$. In spite of using the same solid surface density in the casting process for all the film samples, some differences were found. In general, the films containing oils were thicker than the S-PVA blend, whereas AgNPs composite films were the thinnest. Zivanovic et al. [24], Benavides et al. [25] and Wu et al. [26] also described an increase in the film thickness as a result of the weakening of the interchain forces provoked by the interactions between the oil and polymers [27]. On the contrary, AgNPs seems to provoke a greater chain aggregation due to the more intense interaction forces, leading to a greater film compactness.

\subsection{Disintegration test}

The degree of disintegration (D) of films when exposed to laboratory-scale composting environmental conditions ( $58 \pm 2{ }^{\circ} \mathrm{C}$ for 73 days) provided informed about the physical breakdown of the material into smaller fractions. The test was validated according to the standard method, which established a reduction $(R)$ of the volatile-solid content in the 
sample of the compost of over $30 \%$, with a standard deviation for $\% D_{73}$ values of less than 10 units. In the performance tests, $R$ ranged between $55 \pm 4$ and $62 \pm 2 \%$, and the standard deviations for $\% D_{73}$ values were lower than 10 as shown in Table 1.

The disintegration values $\left(D_{73}\right)$ of pure starch and PVA films were $97 \pm 3 \%$ and $3 \pm 2 \%$, respectively. The values found for blend films with and without antimicrobials, shown in Table 2, revealed that S-PVA films exhibited intermediate $D_{73}$ values $(60 \pm 4)$, between those obtained for both pure S and PVA films in agreement with the results reported by Azahari et al. [15]. Hashimoto et al. [28] reported that the bacteria capable of degrading PVA are commonly distributed in various environments, but a long period is necessary to observe a visible PVA-degrading activity.

The incorporation of active substances significantly increased the $D_{73}$ values (Table 1), this effect only being significant when using the highest concentration of the essential oils and more than 2.1 wt.\% of silver species in the total film solids (samples S-PVA- 3Ag, S-PVA$4 \mathrm{Ag})$. Several authors have attributed this effect to the lower mechanical resistance of these samples [29], in line with the fact that the continuity of the polymer network is interrupted by the presence of oil droplets/solid particles and the weaker interactions between polymer chains, enhancing the matrix erosion.

The visual appearance of the recovered films after different times of disintegration is shown in Figure 1, where the different degradable character of the samples can be observed. At the beginning of the process, all of the films exhibited a continuous structure with no visible holes. It is also possible to observe that the PVA films were more transparent than S films, in agreement with that previously reported [6]. The incorporation of antimicrobial oils conferred opacity and yellowness on the films, while the AgNPs led to brownish films as a consequence of the silver reduction to form silver nanoparticles. This generated a yellowish brown colour attributed to their characteristic surface plasmon resonance [20]. These effects were more marked when the concentration of the antimicrobial agents rose in the films. 
After the composting process, S films were completely disintegrated while PVA films were hardly degraded. Blend films with and without antimicrobial agents exhibited an intermediate behavior, as commented on above. In the case of silver loaded films, some metallic silver spots appeared throughout the time, in all likelihood due to the agglomeration of silver particles.

Figure 2 shows the development of the film surface area $\left(\mathrm{mm}^{2}\right)$ for S, PVA and S-PVA films with and without antimicrobials at different times under composting conditions. Two different types of behavior were observed. On the one hand, the surface of some films (S, blend films with OEO and silver loaded films) continuously decreased throughout the composting period, or even completely disappeared after 14 days (as in the case of S films). This fast disintegration of the pure starch films could be related to the high degree of water diffusion into the matrix, due to its highly hydrophilic nature $[15,30,31]$.

On the other hand, neat PVA films and blends with NO underwent a surface expansion during the first 14 days, attributed to the water absorption and the subsequent swelling of the polymer network. Afterwards, a gradual reduction in their surface area was observed. The differences observed between both film groups can be explained taking into account the rate at which the different phenomena involved in the degradation process occur: in the first group (where no swelling is detected), the degradation rate of the polymer backbone seems to be faster than the diffusion of water penetrating through the polymer. In this case, surface erosion occurred quickly, without enough time for water diffusion through the material and film swelling. In the second film group, the water diffusion process was faster than the degradation process; then, the polymer swelled and bulk erosion was delayed [32]. In Table 1, the total surface reduction in the films after the composting period is shown. The surfaces of S-PVA films were reduced by around $35 \pm 7 \%$ and, in general, the incorporation of antimicrobial agents led to significantly greater values (around $60 \%$, regardless of the type of antimicrobial), in agreement with the disintegration (D) values.

\subsection{Structure of films throughout the composting period}


Figure 3 (a) shows the optical microscopy images of S, PVA and blend films before the composting process. S films exhibited a homogenous microstructure which was much more disordered than the smooth surface shown by PVA, in which the alignment of the polymer chains can be deduced. Blend films were more heterogeneous, due to the lack of polymer miscibility and the co-existence of two phases, as previously reported $[6,30]$. At the end of the composting process (Figure 3b), PVA and blend films exhibited more disordered and fragile structures. Images of pure S films at the end of the composting period are not shown because they completely disintegrated after 7 days.

The incorporation of the different active compounds led to a film of differing structure and appearance, with respect to the S-PVA films, especially before the composting period (Figure 3). The incorporation of OEO provoked films with a coarser structure in comparison with those containing NO. The different nature of the lipids and the interactions established with the polymer network will define the final structure, appearance and mechanical resistance of the composite films [33].

Films incorporating different contents of AgNPs showed similar structures to S-PVA films at the magnification level of the microscopic observations (images no shown). The composting time affected the observed film structure in every case, giving rise to more porous systems, where holes could be observed in some cases.

\subsection{Thermogravimetric behaviour}

Changes in the thermal decomposition of S, PVA and S-PVA films during the composting process was studied through TGA and DTG curves (Figure 4). S-PVA films with antimicrobial substances (data not shown) exhibited similar behavior to the S-PVA blend. Starch and PVA films exhibited an initial degradation step, around $100^{\circ} \mathrm{C}$, related with water loss. Moreover, starch showed a typical main decomposition step with a maximum degradation rate centered at $315^{\circ} \mathrm{C}$. On the contrary, pure PVA films exhibited two process steps: the first one occurred between 260 and $357^{\circ} \mathrm{C}$ (sample weight loss about $80 \%$ ), in 
which the dehydration of the PVA takes place, followed by chain scission and decomposition [34]. The second step, around 387 and $450 \stackrel{\circ}{\circ}$, was attributed to the degradation of the by-products generated by PVA during the thermal process [35]. In the case of S-PVA blend films incorporating or not antimicrobials, three process steps were observed. Their onset $\left(T_{0}\right)$, peak $\left(T_{p}\right)$ and end $\left(T_{e}\right)$ temperatures for these degradation steps before and after the composting process are shown in Table 2. In these S-PVA films, the first step shows a maximum degradation rate $\left(T_{p}\right)$ at a relatively low temperature, around $200 \stackrel{\circ}{ } \mathrm{C}$, attributed to the thermo-degradation of the blend, when PVA hydroxyl groups react with those of starch chains through the formation of oxi (-O-) groups and subsequent water loss $[30,36]$. The second and third steps were similar to those observed for pure starch and PVA films, showing peak temperatures at 305 and $417^{\circ} \mathrm{C}$, respectively. These results agree with those previously reported by Sreekumar et al. [36] and Cano et al. [30] for starch:PVA films with different polymer ratios.

The addition of antimicrobial oils (Oregano and Neem) did not significantly affect $(p>0.05)$ the onset, peak and end temperatures of the three degradation processes. Nevertheless, silver-loaded films were less thermostable $(p<0.05)$, as they exhibited lower $T_{0}$ and $T_{p}$ values especially when the silver content of the films rose. The presence of ions $\left(\mathrm{NO}_{3}{ }^{-}\right)$and silver species could reduce the extent of the polymer chain interactions, in line with the effect of the ionic strength on the chain-folding degree in the film-forming dispersion, thus reducing the film thermal stability.

The influence of the composting time was noticeable for the first and second thermal degradation steps of S-PVA films. The first step disappeared in every sample, coherently with the degradation of starch, which is not notably present in the degraded films. In general, the temperatures of the second step increased for samples biodegraded for 73 days, which suggests that the residual components in the films were also the most thermostable. This behavior has also been observed in pure PVA films by Tudorachi et al. [37] for different SPVA ratios. Therefore, a faster degradation of the least thermo-resistant species occurred during the composting process. 
The percentage of residual mass at $600^{\circ} \mathrm{C}$ is also shown in Table 2. All of the formulations showed low pyrolysis residual mass, which in some cases, increased $(p<0.05)$ at the end of the composting period.

\subsection{Biodegradation behaviour}

The biodegradability of films was evaluated by submitting the samples to laboratory-scale composting environmental conditions ( $58 \pm 2{ }^{\circ} \mathrm{C}$ for 45 days). Prior to the test, the theoretical maximum quantity of carbon dioxide that can be produced by the biodegradation of the samples was calculated from their carbon content, which was determined by elemental analysis (Table 3). Cellulose microcrystalline (CMC) was also evaluated and used as positive reference.

Figure 5 shows the biodegradation kinetics in terms of percentage of biodegradation (Eq. 6) as a function of time for CMC, S, PVA and S-PVA films (Figure 5a) and for S-PVA films containing the highest concentration of antimicrobials (S-PVA-2O, S-PVA-2N and S-PVA4Ag) (Figure 5b).

Starch and CMC exhibited the characteristic sigmoid profiles of respirometric tests with three different phases (an initial lag period lasting 2-8 days, a biodegradation phase and a plateau), in agreement with that reported by Balaguer et al. [10]. For both polysaccharides, glycosidases are responsible for the cleavage of glycosidic bonds, amylases act on starch hydrolyzing the $\alpha-1,4$ and/or $\alpha-1,6$ glucoside linkages and cellulases act on cellulose $\beta-1,4$ glucoside linkages [38]. Both, water-induced hydrolysis in the polymer films and enzymatic degradation caused by microorganisms contribute to biodegradation.

On the other hand, pure PVA films exhibited a flatter biodegradation profile, similar to that reported by Chiellini et al. [39]. In the initial biodegradation step, the specific oxidation of 1,3- hydroxyl groups, mediated by oxidase and dehydrogenase type enzymes, is carried out to give $\beta$-hydroxilketones as well as 1,3 -diketone moieties. The latter entities are 
susceptible to carbon-carbon bond cleavage promoted by specific $\beta$-diketone hydrolase, giving rise to the formation of carboxyl and methyl ketone end groups [39].

Starch films completely biodegraded $(B=100 \%)$ after 32 days. After 45 days, they reached biodegradation percentages of over $100 \%$ (134 \%) which was also observed for S-PVA$2 \mathrm{~N}$. This effect is attributed to the priming effect, which occurs when the compost inoculum in the test reactor containing the samples is producing more $\mathrm{CO}_{2}$ than the compost inoculum in the blank reactors, due to the stimulation of organic matter mineralization that occurs after the addition of easily-decomposable organic matter $[40,41]$. However, the mechanism by which priming effects are produced remains unknown [42], but it is believed that it is a natural process, a consequence of the interaction of microorganisms and organic matter [10].

S-PVA films exhibited an intermediate degradation profile between that shown by the pure polymeric films due to the faster degradation of starch [15, 17, 39], thus suggesting that the vinyl polymer did not affect the microbial assimilation of the blend film under composting exposure.

The incorporation of antimicrobial oils followed the same biodegradation profile trend as SPVA films, whereas the silver films behaved completely differently, exhibiting an active initial composting stage followed by a plateau period (Figure 5b). This difference must be due to the greater antimicrobial activity of silver and to the fact that it lasts longer in the environment, in comparison to Oregano and Neem oil.

Table 4 shows the percentage of film biodegradation after 45 days $\left(B_{45}\right)$ under controlled composting conditions. CMC reached a biodegradation level of $79 \%$ after 45 days, in agreement with the level established by the ISO 14855 standard. The same percentage was obtained by Du et al. [13] for this material. PVA films reached a biodegradation level of $54 \%$ after 45 days. Different authors have reported the important role played by both the composting temperature and the type of active sludge on the biodegradation behavior of PVA [14, 39]. 
The incorporation of antimicrobial substances tended to provide poorer biodegradation percentages $\left(B_{45}\right)$, especially in samples containing silver (Table 4). Similar behaviour was found by Balaguer et al. [10], for gliadin films containing cinmaldehyde. Nevertheless, no significant differences in the $B_{45}$ values were found for the different film formulations if data variability is considered. Biodegradation curves were fitted to Hill's equation (Eq. 7 ) and the fitting parameters are reported in Table 4. As expected after the obtained results, the maximum biodegradation percentage corresponded to the $S$ films $(148 \%$, due to the priming effect) while the minimum was observed for PVA films (56\%). The S-PVA blend films reached values of $102 \%$, which was closer to that found for pure S film. The presence of active antimicrobial compounds does not inhibit the biodegradation process of film matrices, but they tend to reduce the percentage of the final biodegradation level, depending on the antimicrobial effectiveness of the film. The most active antimicrobial films (silver loaded) exhibited the lowest $\mathrm{B}_{45}$ values.

In general, about 15 days were required to reach a biodegradation level of $50 \%$ (k values) in the films, except for pure PVA, S-PVA blends and films containing silver. 23-25 days were needed for pure PVA and S-PVA blends, whilst films with silver only needed 6 days, coherently with the differences in the biodegradation pattern of these samples.

Figure 6 shows the biodegradation rates obtained from the first derivative of Hill's equation as a function of time, for each film. Table 4 shows the maximum biodegradation rate $\left(\tau_{\max }\right)$ and the time needed to reach the maximum biodegradation rate $\left(t_{\max }\right)$. PVA films and the blend S-PVA films without antimicrobials exhibited the lowest, most constant biodegradation rate, reaching a maximum of 2.2-2.8\%/day after 19 and 3 days, respectively. CMC, starch and S-PVA containing antimicrobial oils exhibited similar biodegradation rates, of about 5 to $7 \% /$ day, after 9-12 days, respectively. Silver-loaded films showed the maximum biodegradation rate (about $15 \% /$ day) after 6 days of composting exposure. Afterwards, a sharp decrease in the biodegradation rate was observed until the $15^{\text {th }}$ day of composting. This behavior could be associated with changes in the culture medium, where the release of the antimicrobial compounds could affect the compost microbial activity [10, 43]. 


\section{Conclusion}

S-PVA films exhibited an intermediate biodegradation and disintegration behavior between those with pure S and PVA films. The addition of antimicrobial substances enhanced film disintegration, due to the introduction of structural discontinuities in the polymer network; the greater the antimicrobial content, the more intense the effect. Likewise, antimicrobials affected the biodegradation profile of starch-PVA films, depending on the type and concentration of the compounds. Neem and oregano essential oils slightly decreased the maximum percentage of biodegradation without affecting the time needed to reach this maximum. However, silver species completely changed the biodegradation profile of the films, slowing the degradation rate and reducing the degradation extent, suggesting a partial alteration of the compost inoculum.

On the basis of the obtained results, it is possible to conclude that the concentrations of antimicrobial oils used did not apparently compromise the degradation of active S-PVA films. Thus, these active compounds provided the films with additional functional properties while, at the same time, satisfying the present-day consumer demand for environmentallyfriendly technologies. In the case of silver-loaded films, low silver concentrations are recommended in the dried film in order to avoid serious alterations in the biodegradation process. In the future, in vivo eco-toxicity studies will be carried out in order to evaluate the possible negative biological effect exerted by the metabolites from the biodegradation of these antimicrobial films.

\section{Acknowledgements}

The authors acknowledge the financial support from the Spanish Ministerio de Economía y Competitividad through the projects AGL2013-42989-R. Amalia Cano also thanks the Spanish Ministerio de Educación, Cultura y Deporte for the FPU grant. 


\section{References}

1. Alvira, M.I. (2007). Los plásticos como residuos Antecedentes y Problemática Ambiental. Boletin Ambiental IDEA, Universidad Nacional de Colombia.

2. Avérous, L., \& Pollet, E. (2012). Biodegradable polymers. In L. Avérous \& E. Pollet (Eds), Environmental Silicate Nano-Biocomposites (pp. 13-39). Springer-Verlag, London. ISBN: 978-1-4471-4101-3. DOI: 10.1007/978-1-4471-4108-2_2.

3. European Parliament and Council directive 94/62/EC of 20 December 1994 on packaging and packaging waste.

4. Corrales, M., Fernández, A., \& Han, J.H. (2014). Chapter 7, Antimicrobial packaging systems. In J. H. Han (Ed.), Innovations in food packaging (second edition) (pp. 133170). Academia Press: San Diego, CA, USA.

5. Lanciotti, R., Gianotti, A., Patrignani, F., Belletti, N., Guerzoni, M.E., \& Gardini, F. (2004). Use of natural aroma compounds to improve shelflife and safety of minimally processed fruits. Trends in Food Science \& Technology, 15, 201-208.

6. Cano, A. I., Cháfer, M., Chiralt, A., \& González-Martínez, C. (2015). Physical and microstructural properties of biodegradable films based on pea starch and PVA. Journal of Food Engineering. http://dx.doi.org/10.1016/j.jfoodeng.2015.06.003.

7. Aguirre, A., Borneo, R., \& León, A. E. (2013). Antimicrobial, mechanical and barrier properties of triticale protein in films incorporated with oregano essential oil. Food Bioscience, 1, 2-9.

8. Martínez-Abad, A., Lagarón, J. M., \& Ocio, M.J. (2014). Antimicrobial beeswax coated polylactide films with silver control release capacity. International Journal of Food Microbiology, 174, 39-46.

9. Sánchez-González, L., González-Martínez, C., Chiralt, A., \& Cháfer, M. (2011b). Use of Essential Oils in Bioactive Edible Coatings. Food Engineering Review, 3, 116. 
10. Balaguer, M. P., Villanova, J., Cesar, G., Gavara, R., \& Hernández-Muñoz, P. (2015). Compostable properties of antimicrobial bioplastics base don cinnamaldehyde cross-linked gliadins. Chemical Engineering Journal, 262, 447455.

11. Fortunati, E., Luzi, F., Plugia, D., Dominici, F., Santulli, C., Kenny, J.M., \& Torre, L. (2014). Investigation of thermo-mechaical, chemical and degradative properties of PLA-limonene films reinforced with cellulose nanocrystals extracted from Phormium tenax leaves. European Polymer Journal, 56, 77-91.

12. Avella, M., De Vlieger, J. J., Errico, M. E., Fischer, S., Vacca, P., \& Volpe, M.G. (2005). Biodegradation starch/clay nanocomposite films for food packaging applications. Food Chemistry, 93, 467-474.

13. Du, Y. L., Cao, Y., Fang, L., Li, F., Cao, Y., Wang, X-L., \& Wang, Y-Z. (2008), Biodegradation behaviours of thermoplastic starch (TPS) and thermoplastic dialdehyde starch (TPDAS) under controlled composting conditions. Polymer Testing, 27, 924-930.

14. Julinová, M., Kupec, J., Alexy, P., Hoffmann, J., Sedlařik, V., Vojtek, T., Chromčáková, J., \& Bugaj, P. (2010). Lignin and starch as potential inductors for biodegradation of films based on poly(vinyl alcohol) and protein hydrolysate. Polymer Degradation and Stability, 95, 225-233.

15. Azahari, N. A., Othman, N., \& Ismail, H. (2011). Biodegradation studies of polyninyl alcohol/corn starch blend films in solid and solution media. Journal of Physical Science, 22(2), 15-31.

16. Chen, L., Iman, S. H., Gordon, S. H., \& Greène, R. V. (1997). Starch-polyvinyl alcohol crosslinked films-performance and biodegradation. Journal of Environmental Polymer Degradation, 5 (2), 111-117.

17. Jayasekara, R., Harding, I., Bowater, I., \& Christie, G. B. Y. (2003). Biodegradation by composting of surface modified starch and PVA blended films. Journal of Polymers and the Environment, 11 (2), 49-56. 
18. Cano, A., Jiménez, A., Cháfer, M., González, C., \& Chiralt, A. (2014). Effect of amylose:amylopectin ratio and rice bran addition on starch films properties. Carbohydrate Polymers, 111, 543-555.

19. Monge, M. (2009). Silver nanoparticles: methods of synthesis by dissolution and bactericidal properties. Anales de la Real Sociedad Española de Química, ISSN 1575-3417, 1, 33-41.

20. Torres-Castro, A., González, V. A., Garza, M., \& Gauna, E. (2011). Síntesis de nanocompósitos de plata con almidón. Ingenierías, 50 (14), 34-41.

21. ISO 20200. 2004. Plastics- Determination of the deree of disintegration of plastic materials under simulated composting in a laboratory-scale test.

22. UNE-EN ISO 14855-1: 2012. Determinación de la biodegradabilidad aeróbica final de materiales plásticos en condiciones de compostaje controladas. Método según el análisis de dióxido de carbono generado. Parte 1: Método general.

23. Arrieta, M. P., Fortunati, E., Dominici, F., Rayón, E., López, J., \& Kenny, J. M. (2014). PLA-PHB/ cellulose based films: Mechanical, barrier and disintegration properties. Polymer Degradation and Stability, 107, 139-149.

24. Zivanovic, S., Chi, S., \& Draughon, A.F. (2005). Antimicrobial activity of Chitosan films enriched with essential oils. Journal of Food Science, 70 (1), M45-M51.

25. Benavides, S., Villalobos-Carvajal, R., \& Reyes, J.E. (2012). Physical, mechanical and antibacterial properties of alginate films: Effect of the crosslinking degree and oregano essential oil concentration. Journal of food engineering, 110, 232-239.

26. Wu, S. G., Liu, H., Wang, S., Chen, S., Wan, J., Li, J., \& Zhang, Q. (2014). Properties and antimicrobial activity of silver carp (Hypophthamichthys molitrix) skin gelatinchitosan films incorporated with oregano essential oil for fish preservation. Food Packaging and Shelflife, 2, 7-16. 
27. Cano, A., Cháfer, M., Chiralt, A., \& González-Martínez, C. (2016). Physical and antimicrobial properties of starch-PVA blend films as affected by the incorporation of natural antimicrobial agents. Foods, 5, 3; doi:10.3390/foods5010003.

28. Hashimoto, S., \& Ozaki, Y. (1980). Study on treatment of recalcitrant substances by activated sludge. J Jpn Sew Works Assoc, 17, 17-26.

29. Rhim, J. W., Wang, L. F., \& Hong, S. I. (2013). Preparation and characterization of agar/silver nanoparticles composite films with antimicrobial activity. Food Hydrocolloids, 327-335.

30. Cano, A., Fortunati, E., Cháfer, M., Kenny, J.M., Chiralt, A., \& González-Martínez, C. (2015). Properties and ageing behaviour of pea starch films as affected by blend with poly(vinyl alcohol). Food Hydrocolloids, 48, 84-93.

31. Jiménez, A., Fabra, M.J., Talens, P., \& Chiralt, A. (2012). Edible and biodegradable starch films: a review. Food Bioprocess Thecnol, 5, 2058-2076.

32. Burkersroda, F. V., Schedl, L., \& Gopferich, A. (2002). Why degradable polymers undergo surface erosion or bulk erosion. Biomaterials, 23, 4221-4231.

33. Fabra, M. J., Jiménez, A., Atarés, L., Talens, P., Chiralt, A. (2009). Effect of fatty acids and beeswax addition on properties of sodium caseinate dispersions and films. Biomacromolecules, 10, 1500-1507.

34. Frone, A. N., Panaitescu, D. M., Donescu, D., Spataru, C. I., Radovici, C., \& Trusca, R. (2011). Preparation and characterization of PVA composites with cellulose nanofibers obtained by ultrasonication. BioResources, 6, 487-512.

35. Bonilla, J., Fortunati, E., Atar_es, L., Chiral, A., \& Kenny, J. M. (2014). Physical, structural and antimicrobial properties of poly vinyl alcohol-chitosan biodegradable films. Food Hydrocolloids, 35, 463-470.

36. Sreekumar, P. A., Al-Harthi, M. A., \& De, S. K. (2012). Studies on compatibility of biodegradable starch/polyvinyl alcohol blends. Polymer Engineering and Science, 52(10), 2167-2172. 
37. Tudorachi, N., Cascaval, C. N., Rusu, M., \& Pruteanu, M. (2000). Testing of polyvinyl alcohol and starch mixtures as biodegradable polymeric materials. Polymer Testing, 19, 785-799.

38. Whitaker, J.R. (1994). Principles of Enzymology for the Food Sciences, Marcel Dekker, Inc., New York.

39. Chiellini, E., Corti, A., D'Antone, S., \& Solaro, R. (2003). Biodegradation of poly (vinyl alcohol) based materials. Progress in Polymer Science, 28, 963-1014.

40. Shen, J., \& Bartha, R. (1997). Priming effect of glucose polymers in soil based biodegradation tests. Soil Bid. Biochem, 29, (8), 1195-1198.

41. Kuzyakov, Y., Friedel, J.K., \& Stahr, K. (2000). Review of mechanisms and quantification of priming effects. Soil Biology and Biochemestry, 32, 1485-1498.

42. Fontaine, S., Mariotti, A., \& Abbadie, L. (2003). The priming effect of organic matter: a question of microbial competition. Soil Biology \& Biochemistry, 35, 837-843.

43. Domenek, S., Feuilloley, P., Gratraud, J., Morel, M. -H., \& Guilbert, S. (2004). Biodegradability of wheat gluten based bioplastics. Chemosphere, 54, 551-559. 
Table 1. Different S-PVA active films (and sample codes) showing the ratio of antimicrobial agents (NO, OEO or $\mathrm{AgNO}_{3}$ ) with respect to starch and their wt. percentage with respect to the total film solids. Film's moisture content (MC) and thickness (mm) before the composting process and percentage of disintegration $\left(\% D_{73}\right)$ and surface reduction $\left(\Delta S_{73}\right)$ of the films after 73 days under aerobic composting conditions.

\begin{tabular}{lccc|cccc}
\hline $\begin{array}{l}\text { Antimicrobial } \\
\text { (AA) }\end{array}$ & S:AA ratio & wt.\% (d.b.) & Sample code & MC (\% d.b.) & Thickness (mm) & $\% D_{73}$ & $\Delta S_{73}(\%)$ \\
\hline Without AA & & & & & & \\
\hline Neem oil (N) & $1: 0.125$ & 6.7 & S-PVA-1N & $5.13 \pm 0.09^{\mathrm{a}}$ & $0.073 \pm 0.006^{\mathrm{b}}$ & $59 \pm 3^{\mathrm{ab}}$ & $31 \pm 2^{\mathrm{a}}$ \\
& $1: 0.5$ & 22.2 & S-PVA-2N & $5.6 \pm 0.7^{\mathrm{ab}}$ & $0.074 \pm 0.011^{\mathrm{b}}$ & $68 \pm 3^{\mathrm{c}}$ & $60 \pm 19^{\mathrm{b}}$ \\
\hline Oregano & $1: 0.125$ & 6.7 & S-PVA-1O & $6.4 \pm 0.2^{\mathrm{cd}}$ & $0.064 \pm 0.003^{\mathrm{a}}$ & $63 \pm 2^{\mathrm{abc}}$ & $57 \pm 6^{\mathrm{b}}$ \\
essential oil (O) & $1: 0.5$ & 22.2 & S-PVA-2O & $6.65 \pm 0.13^{\mathrm{d}}$ & $0.074 \pm 0.014^{\mathrm{b}}$ & $64 \pm 2^{\mathrm{bc}}$ & $55.6 \pm 1.4^{\mathrm{b}}$ \\
\hline & $1: 0.006$ & $0.2^{*}$ & S-PVA-1Ag & $6.06 \pm 0.13^{\mathrm{bc}}$ & $0.063 \pm 0.004^{\mathrm{a}}$ & $60.24 \pm 1.1^{\mathrm{ab}}$ & $50.4 \pm 1.1^{\mathrm{b}}$ \\
Silver nitrate (Ag) & $1: 0.06$ & $2.1^{*}$ & S-PVA-2Ag & $6.33 \pm 0.14^{\mathrm{cd}}$ & $0.058 \pm 0.004^{\mathrm{c}}$ & $63.8 \pm 1.0^{\mathrm{bc}}$ & $45 \pm 20^{\mathrm{ab}}$ \\
& $1: 0.16$ & $5.3^{*}$ & S-PVA-3Ag & $6.0 \pm 0.2^{\mathrm{bc}}$ & $0.059 \pm 0.004^{\mathrm{c}}$ & $63.7 \pm 0.5^{\mathrm{bc}}$ & $68 \pm 20^{\mathrm{b}}$
\end{tabular}

${ }^{*}$ wt of silver with respect to the total solids of the films.

$a, b, c, d, e$ different letters in the same column indicate significant differences among formulations $(p<0.05)$. 
Table 2. Onset, peak and end temperatures ( $T_{0}, T_{p}, T_{e}$ respectively) and residual mass obtained from TGA analysis of S-PVA blend films before and after 73 days of the composting process.

\begin{tabular}{|c|c|c|c|c|c|c|c|c|c|c|c|}
\hline \multirow[b]{2}{*}{ Films } & \multirow{2}{*}{$\begin{array}{l}\text { Time } \\
\text { (days) }\end{array}$} & \multicolumn{3}{|c|}{ First degradation step (starch fraction) } & \multicolumn{3}{|c|}{ Second degradation step (PVA fraction) } & \multicolumn{3}{|c|}{ Third degradation step (PVA fraction) } & \multirow{2}{*}{$\begin{array}{l}\text { Residual mass } \\
600{ }^{\circ} \mathrm{C}(\%)\end{array}$} \\
\hline & & $\overline{T_{0}}$ & $T_{p}$ & $\mathrm{~T}_{\mathrm{e}}$ & $\mathrm{T}_{0}$ & $T_{p}$ & $\mathrm{~T}_{\mathrm{e}}$ & $\mathrm{T}_{0}$ & $T_{p}$ & $\mathrm{~T}_{\mathrm{e}}$ & \\
\hline \multirow{2}{*}{ S-PVA } & 0 & $163 \pm 12^{\mathrm{a}}$ & $210 \pm 7^{\mathrm{ab}}$ & $244 \pm 3^{a}$ & $262.3 \pm 1.6^{\mathrm{a} 1}$ & $305.3 \pm 0.7^{\mathrm{a}} 1$ & $357.4 \pm 1,7^{\mathrm{a} 1}$ & $387,8 \pm 1,7^{\mathrm{a} 1}$ & $417 \pm 2^{\mathrm{a} 1}$ & $447 \pm 3^{a 1}$ & $13.7 \pm 0.3^{\mathrm{a}} 1$ \\
\hline & 73 & & & & $264 \pm 6^{\mathrm{a} 1}$ & $316 \pm 6^{\mathrm{a} 2}$ & $362 \pm 8^{\mathrm{a} 1}$ & $390 \pm 3^{a 1}$ & $421.3 \pm 1.4^{\mathrm{a}}$ & $457 \pm 2^{\mathrm{a} 1}$ & $24 \pm 3^{\underline{a} 2}$ \\
\hline \multirow{2}{*}{ S-PVA-1O } & 0 & $150 \pm 21^{\mathrm{abc}}$ & $202 \pm 5^{\text {ac }}$ & $238.6 \pm 0.3^{a b}$ & $258.2 \pm 0.7^{\mathrm{a} 1}$ & $307.09 \pm 0.12^{\mathrm{a} 1}$ & $305 \pm 69^{\mathrm{b} 1}$ & $393 \pm 3^{\mathrm{a} 1}$ & $431 \pm 10^{\mathrm{b} 1}$ & $458 \pm 12^{\mathrm{a} 1}$ & $15.24 \pm 0.05^{\mathrm{a} 1}$ \\
\hline & 73 & & & & $267 \pm 2^{\underline{a} 2}$ & $320.4 \pm 1.5^{\mathrm{ab} 2}$ & $369 \pm 6^{\underline{a} 2}$ & $390 \pm 3^{a 1}$ & $420 \pm 3^{\mathrm{a} 2}$ & $458 \pm 2^{\mathrm{a} 1}$ & $22 \pm 2^{a} 1$ \\
\hline \multirow{2}{*}{ S-PVA-2O } & 0 & $169 \pm 5^{a}$ & $210.5 \pm 0.5^{\mathrm{ab}}$ & $243.9 \pm 0.2^{\mathrm{abc}}$ & $261.59 \pm 1.06^{\mathrm{a} 1}$ & $311.0 \pm 1.2^{\mathrm{a} 1}$ & $361 \pm 7^{\mathrm{a} 1}$ & $389 \pm 8^{\mathrm{a} 1}$ & $423 \pm 2^{\mathrm{ab} 1}$ & $457 \pm 7^{\mathrm{a} 1}$ & $11.6 \pm 1.2^{\mathrm{a}^{1} 1}$ \\
\hline & 73 & & & & $269 \pm 10^{\mathrm{a} 1}$ & $325 \pm 9^{\mathrm{b} 2}$ & $372 \pm 10^{\mathrm{a} 1}$ & $390 \pm 6^{\mathrm{a} 1}$ & $419 \pm 4^{\mathrm{a} 1}$ & $452 \pm 2^{\mathrm{a} 1}$ & $25 \pm 10^{\underline{a} 2}$ \\
\hline \multirow{2}{*}{ S-PVA-1N } & 0 & $168 \pm 3^{a}$ & $213.4 \pm 1.8^{\mathrm{b}}$ & $247.1 \pm 0.9^{a c}$ & $265.2 \pm 0.2^{\mathrm{a} 1}$ & $307.3 \pm 0.2^{\mathrm{a} 1}$ & $362.4 \pm 1.8^{\mathrm{a} 1}$ & $394 \pm 3^{a 1}$ & $421 \pm 2^{\mathrm{a} 1}$ & $448 \pm 1^{\mathrm{a} 1}$ & $12.9 \pm 0.9^{\mathrm{a}} 1$ \\
\hline & 73 & & & & $266.6 \pm 1.7^{a} 1$ & $320.4 \pm 0.6^{\mathrm{ab} 2}$ & $373 \pm 2^{a 1}$ & $392 \pm 2^{\mathrm{a} 1}$ & $420.3 \pm 1.3^{\mathrm{a} 1}$ & $457.4 \pm 0.4^{\mathrm{a} 1}$ & $23.42 \pm 1.02^{\mathrm{a} 2}$ \\
\hline \multirow{2}{*}{ S-PVA-2N } & 0 & $157 \pm 3^{a}$ & $206 \pm 2^{\mathrm{ab}}$ & $292 \pm 69^{c}$ & $263.2 \pm 1.3^{a 1}$ & $308.42 \pm 0.12^{\mathrm{a} 1}$ & $397 \pm 23^{a 1}$ & & & & $9.5 \pm 0.3^{\mathrm{a} 1}$ \\
\hline & 73 & & & & $266.4 \pm 0.2^{\mathrm{a} 1}$ & $323 \pm 2^{\mathrm{b} 2}$ & $375 \pm 8^{a} 1$ & $391 \pm 7^{\mathrm{a} 1}$ & $419 \pm 6^{a}$ & $453.7 \pm 1.2^{\mathrm{a}}$ & $24 \pm 2^{\mathrm{a} 2}$ \\
\hline \multirow{2}{*}{ S-PVA-1Ag } & 0 & $153.36 \pm 1.14^{\mathrm{ab}}$ & $193.5 \pm 0.7^{c}$ & $225.7 \pm 0.9^{\mathrm{ab}}$ & $243.8 \pm 0.4^{\mathrm{b} 1}$ & $286.8 \pm 0.8^{\mathrm{b} 1}$ & $338.7 \pm 1.3^{b 1}$ & $369 \pm 5^{\mathrm{b} 1}$ & $396 \pm 5^{c 1}$ & $421 \pm 5^{\mathrm{b} 1}$ & $17.0 \pm 1.7^{\mathrm{ab} 1}$ \\
\hline & 73 & & & & $238 \pm 7^{\mathrm{b} 1}$ & $295 \pm 5^{\mathrm{b} 2}$ & $340 \pm 7^{\mathrm{b} 1}$ & $354 \pm 8^{b 1}$ & $385 \pm 9^{b 1}$ & $439.6 \pm 0.3^{b 1}$ & $19.75 \pm 1.06^{\mathrm{a} 1}$ \\
\hline \multirow{2}{*}{ S-PVA-2Ag } & 0 & $135 \pm 3^{b c d}$ & $181.9 \pm 0.8^{d}$ & $227,8 \pm 1.5^{\mathrm{ab}}$ & $246.9 \pm 0.9^{b 1}$ & $287 \pm 2^{b 1}$ & $333 \pm 5^{\mathrm{b} 1}$ & & & & $21.21 \pm 0.09^{\mathrm{ab} 1}$ \\
\hline & 73 & & & & $216 \pm 4^{\mathrm{c} 2}$ & $282 \pm 8^{c 1}$ & $331 \pm 8^{\mathrm{b} 1}$ & & & & $30 \pm 12^{\mathrm{a} 1}$ \\
\hline \multirow{2}{*}{ S-PVA-3Ag } & 0 & $133.4 \pm 0.9^{\mathrm{cd}}$ & $169.6 \pm 0.4^{\mathrm{e}}$ & $216.83 \pm 1.15^{\mathrm{ab}}$ & $246.1 \pm 0.2^{\mathrm{b} 1}$ & $287.3 \pm 0.4^{b 1}$ & $332 \pm 3^{b 1}$ & & & & $21.25 \pm 0.14^{\mathrm{ab} 1}$ \\
\hline & 73 & & & & $224 \pm 15^{\mathrm{bc} 2}$ & $287.6 \pm 1.8^{\mathrm{bc} 1}$ & $336 \pm 5^{b 1}$ & & & & $27 \pm 6^{\underline{a} 1}$ \\
\hline \multirow{2}{*}{ S-PVA-4Ag } & 0 & $119.5 \pm 1.9^{d}$ & $154 \pm 5^{b}$ & $196 \pm 8^{b}$ & $245.0 \pm 0.2^{b 1}$ & $286.5 \pm 0.9^{b 1}$ & $330.1 \pm 1.4^{b 1}$ & & & & $25 \pm 1^{b 1}$ \\
\hline & 73 & & & & $226 \pm 2^{\mathrm{bc} 2}$ & $289.4 \pm 0.2^{\mathrm{bc} 1}$ & $335.1 \pm 0.2^{\mathrm{b} 1}$ & & & & $31.6 \pm 0.6^{\mathrm{a} 1}$ \\
\hline
\end{tabular}

a, b, c, different letters in the same column indicate significant differences among formulations at the same time of the analysis $(0$ or 73 says) ( $<<0.05)$.

1,2, different numbers in the same column indicate significant differences among times for the same formulation $(p<0.05)$. 
Table 3. Elemental composition (Nitrogen-N, Carbon-C, Hydrogen-H) of cellulose microcrystalline (CMC) and S-PVA blend films with and without antimicrobial agents.

\begin{tabular}{llll}
\hline Sample & $\mathrm{N}(\%)$ & $\mathrm{C}(\%)$ & $\mathrm{H}(\%)$ \\
\hline CMC & $0.145 \pm 0.02$ & $42.2 \pm 0.2$ & $5.9 \pm 1.3$ \\
S-PVA & $0.12 \pm 0.02$ & $44.41 \pm 0.04$ & $4.9 \pm 0.7$ \\
S-PVA-2O & $0.11 \pm 0.02$ & $47.5 \pm 0.2$ & $6.0 \pm 0.6$ \\
S-PVA-2N & $0.11 \pm 0.02$ & $50.745 \pm 0.106$ & $6.8 \pm 1.5$ \\
S-PVA-4Ag & $0.100 \pm 0.014$ & $36.60 \pm 0.03$ & $4.2 \pm 0.6$ \\
\hline
\end{tabular}


Table 4. Hill's parameters $\left(\% B_{\max }, k\right.$ and $\left.n\right)$, percentage of biodegradation after 45 days of composting exposure $\left(\% \mathrm{~B}_{45}\right)$, maximum biodegradation rate $\left(\tau_{\max }\right)$ and time at this maximum ( $\left.t \tau_{\max }\right)$, for the different films and cellulose microcrystalline (CMC, reference).

\begin{tabular}{|c|c|c|c|c|c|c|c|}
\hline \multirow[b]{2}{*}{ Samples } & \multicolumn{4}{|c|}{ Hill's parameters } & \multirow[b]{2}{*}{$\% B_{45}$} & \multirow[b]{2}{*}{$\tau_{\max }(\% B /$ day $)$} & \multirow[b]{2}{*}{$t \tau_{\max }$ (days) } \\
\hline & $\% \mathrm{~B}_{\max }$ & k (days) & $\mathrm{n}$ & $\mathrm{R}^{2}$ & & & \\
\hline CMC & 73 & 13.1 & 5.1 & 0.98 & 79 & 7.4 & 12 \\
\hline$S$ & 148 & 15.2 & 2.0 & 0.94 & 134 & 6.3 & 9 \\
\hline PVA & 56 & 22.8 & 3.3 & 0.85 & 54 & 2.2 & 19 \\
\hline S-PVA & 102 & 25 & 1.2 & 0.92 & 68 & 2.8 & 3 \\
\hline S-PVA-2O & 91 & 14.8 & 2.6 & 0.97 & 88 & 4.7 & 11 \\
\hline S-PVA-2N & 125 & 16.2 & 2.3 & 0.97 & 114 & 5.4 & 11 \\
\hline S-PVA-4Ag & 54 & 5.9 & 6.6 & 0.98 & 58 & 14.7 & 6 \\
\hline \multicolumn{8}{|c|}{$\% B_{\max }:$ Percentage of biodegradation at infinite time } \\
\hline \multicolumn{8}{|c|}{$\mathrm{k}$ : time required to reach $50 \%$ of the maximum biodegradation } \\
\hline \multicolumn{8}{|c|}{$\mathrm{n}$ : curve radius of the sigmoid function } \\
\hline \multicolumn{8}{|c|}{$\% \mathrm{~B}_{45}:$ Percentage of biodegradation after 45 days } \\
\hline
\end{tabular}

